\title{
Architecture "The Inevitable Art": Interactions With and Impacts on the Shape and Design of the Cities
}

\author{
Ali Dashti Shafii, Babak Monir Abbasi, and Shiva Jabari
}

\begin{abstract}
Often it is thought that architecture and urban design are not related and they are totally different identities; however, they have inextricable connection and unawareness of this point can bring about confusion. However, everyday many of architectural decisions are made without paying least attention to it. Today when architecture is presented in various forms and styles, this lack of attention and lack of awareness cause many hazards and for this reason, our cities and towns don't enjoy desirable faces. Although buildings are remarkable individually, their collective impression is disappointing and undesirable. (Richard Hedman and Andrew Jaszweski, 1985) Art, modern architecture and urban structural transition haven't come up suddenly: they are consequences of strong pressures from inside of the societies. The pressures themselves are the result of hasty industrial development and transitional economy. Today, architecture is mostly influenced by fashion and changes are displayed in main aspects of architectural form and identity, whereas in the past, they were only in details. Since we live in an environment which is shaped by man-made structures, architecture is unavoidable art (Ali Madanipour, 2000). In this paper, the writers attempt to deal with the position of architecture in urban design, urban planning in the past and at the present time and structure of cities.
\end{abstract}

Index Terms-Urban planning, modern architecture, structure of cities, city shape, master plan, micropolitan.

\section{INTRODUCTION}

Architecture and urban design are inseparable, but they are often discussed as if there is no connection between them. Talking of one is in fact discussing about another. If the relation of architecture and urban design remain unknown, it may result in chaos or at least confusion and distraction. Nevertheless everyday architectural decisions are made due to lack of knowledge or least attention to their urban outcomes. Today, in the age that many architectural forms and styles are brought up, such carelessness resulted in many dangers so little and big cities are not of satisfactory appearance.

Preservation of orderly, consistent and ideal patterns of development are among the problems of little and big cities, and suburbs [1]. While individual buildings may seem attractive, their collective impression is disappointing and undesirable. The combination of components never integrates into a bigger consistent whole. There appears an absence of strong finalizing and linking patterns. Open spaces around the buildings lack strength, dynamism, and a specific form or identity. Old buildings, remnant of the past,

Manuscript received June 2, 2014; revised Ocotober 20, 2014.

The authors are with the Shomal Universty of Amol, Iran (e-mail: galaxiescomet2002@yahoo.com) can be likened to trashes in the city; lonely pieces lacking past connections, they are now handed to oblivion [2]. At its worst, it is a disconnected and disintegrated world, with unrelated pieces. It presents its residents no meaningful focal point about the blocks they reside in.

On their way to achieve designing unity, societies must conquer some difficulties. Disintegrative effect of automobile, continuous advent of new materials, and inventions in construction routines are some of important factors which come to the mind. These factors, though important, however do not justify or describe the design disorder. Nevertheless, automobile and new construction technology made fundamental changes in the designing of buildings carried out by architects, thus made the development of big and small cities a great and exaggerative work.

Not long ago, it seemed that architecture, with no need of revision, was observing urban designing rules and regulations; there wan an intrinsic sensitivity which supported logical and appropriate harmony and integrity in an artificial environment [3]. But today trends and routines are changed so much that architecture itself causes disorder and inharmony in urban environment; it seems that in the heart of contemporary designing underlies a very fast and intense anti-urban movement. This negative trend has its roots in the early trends of modern architecture.

In speaking of the constitution of an artifact and of its memory, These problems are thought of largely in terms of their collective nature; they pertain to the city, and thus to its collective citizenry. It's maintained that in an art or a science the principles and means of action are elaborated collectively or transmitted through a tradition in witch all the sciences and arts are operating as collective phenomena. But at the same time they are not collective in all their essential parts; individuals carry them out. This relationship between a collective artifact, which is necessarily an urban artifact, and the individual who proposes and single-handedly realizes it can only be understood through a study of the technics by which the artifacts is manifested. There are many different technics; one of them is architecture, and since this is the object of our study, we must here be concerned with it above all, and with economics and history only to the extent that they are manifested in the architectureof the city. The relationship in architecture between the collective urban artifact and the individual is unique with respect to the other technics and arts. In fact, architecture presents itself as a vast cultural movement: it is discussed and criticized well beyond the narrow circle of its specialist; it needs to be realized, to become part of the city, to become "the city." In a certain sense, there is no such thing as buildings that are politically 
"opposed," since the ones that are realized that always those of the dominant class, or at least those which express a possibility of reconciling certain new needs with a specific urban condition. Thus there is a direct relationship between the formulation of certain proposals and the buildings that arise in the city. But it is eqally obvios that this relationship can also be considered in its separate terms. The world of architecture can be seen to unfold and be studied as a logical succession of principles and forms more or less autonomous from the reality of locus and history. Thus, architecture implies the city; but this city may be an ideal city, of perfect and harmonious relationships, where the architecture develops and constructs its own terms of reference. At the same time, the actual architecture of this city is unique; from the very first it has a characteristic and ambiguous relationship that no other art or science possesses. In these terms we can understand the constant polemical urge of architects to design systems in which the spatial order becomes the order of society and attemps to transform society. Modern art and architecture didn't appear suddenly and spontaneously, but they are produced by strong inner society pressures; pressures which were a result of a speedy industrial growth and a changing economy. Enthusiastic blaze of revolution which devoured all enlightenment centers in Europe, gave direction to artworks of the new generation and to the ideals of artists and architects [4], [5]. In the perspective of the new generation, traditional ideas of architecture and urban planning denoted an autocratic society so new forms - produced by modern intellectual and humane thought - ought to substitute them. An all-new movement had begun and architects had to create a modern architecture to address social problems in cities.

Conception of this central idea facilitated the genesis of a whole modern architecture. At the climax of architectural revolution, while the old autocratic symbols were discarded, a substantial factor of the spirit of urban design which was crucially important was also forsaken. What was abandoned was the perception of the concept that urban design is a function of architecture.

Today, architecture is more influenced by fashion. As neckties become wide or narrow, and apparel get tall or short, architectural interests also raise, drop, change and revolutionize [6]. Although in the past, changes were in details, today changes appear in main aspects of form and architectural identity. Achieving a desirable design in the area of architecture and urban planning calls not necessarily for that any decision-maker to be a professional analyzer of designing, but it requires that people who participate in crucial decisions, be aware of what they are going for and to follow.

\section{Architecture And URban Planning, Yesterday AND TODAY}

In the times bygone, architecture was an instrument in the hand of the rich and the authorities, mainly for the purpose of making religious buildings, castles, towers, historic works and blocks, lordly mansions and so on. Making of these blocks were based on the social pyramid; the rich and the powerful on top of the pyramid and the great majority of common people at the bottom of it.

Today, the social pyramid has changed. Castle, towers and great mansions are not of the past demand; they gave their stage to public buildings, hospitals, museums, amphitheaters, libraries, official buildings, bazaars, shopping malls, city halls, colleges and so on. These blocks play many roles on many aspects and public expectations of them are so diverse that buildings must play best any role in the urban environment. This is a characteristic of urban life which calls for an aesthetic approach on the construction design and applying an architectural skill and accuracy in the building process.

\section{NECESSITY FOR REPLANNING}

Many urban buildings are a century old, so many of residential and business blocks may be useless and out of shape. These were city areas which upon an opulence of open spaces and richness of facilities were alacritous and refreshing in the time of development, but gradually changed their face. Intense centralization plus a vast presence of industrial and business activities concluded to increasing growth of urban population which in turn resulted in residential deficit and lot shortage for public uses, manipulation of other land uses, uncontrolled colonization, over-density of constructed areas, shortage of public services and facilities in the cities.

In the beginning, factories were established in the heart of cities, then once-picturesque residential regions were blown by industrial areas and now they are dull environments full of noises, smog and dust, so that those areas became like slums. Also as a result of limited transportation network, transit facilities are insufficient and inappropriate; overflow of automobiles made streets like freeways and the shortage of open spaces, parks, gardens, play grounds, and other recreational facilities is noticeable. These and such faults, caused some problems and damages in the cities, denoting a negligence of civil agents and their indecision on taking action to solve urban concerns. Instead, it is necessary to investigate how certain urban structures come to be identified with the model of a capital, and what relationships are possible between the physical reality of a city and this model.

It is noteworthy that for Europe, but not only for Europe, this model was Paris. This is true to such a degree that it is not possible to understand the structure of many modern capitals. Berlin, Baecelona, Madrid, along with Rome and others. without recognizing this fact. With Paris the entire historical-political process in the architecture of the city takes a specific turn; but the meaning of this relationship can only be discerned by elaborating the specific ways in which it came about. As always, a relationship is established between the urban artifacts structuring the city and the imposition of an ideal project or general scheme, and the pattern o this relationship is very complex. Certainly these are cities that realize their own inclinations and others that do not.

Over time little and big cities are made out of shape or use, so to get out of the abovementioned situation at first a prompt decision must be made for replanning. It is well-known that replanning of a whole new city on vacant lots having no constructional background is easier than replanning of old 
cities. Halprin, as an urban designer, believes that designing a piece of a city is somewhat more complicated than a space mission. Because a space mission has a definite goal, but there is not much unanimity on what is really the best kind of city. Each town or city has its own problems which must be considered to study before any proposal of replanning.

\section{MASTER PLAN}

To compile a successful planning, you should consider the whole city as an individual unit. This is obviously necessary for achieving a comprehensive and harmonious development in a balanced manner or method. Growth and development of a city consumes time and overtime in each era of development, urban growth ought to be controlled based on the rules and regulations of a development plan [7]. Such plan is called Master Plan. Master plan or plan of development is a general design which includes several proposed plans intending to improve existing conditions, and to control future growth of a city in a balanced procedure. Such planning ought to be realistic so as to pragmatically realize its goals while preserving the specific qualities of a given city. Considering that growth of cities is a continuous long term process, the master plan ought not to be inflexible, but it must be correctable so as to provide and supply the city with needed modifications in the future stages of development. Generally a master plan is designed to improve the current or old conditions of cities, but also for constructing a new city on a vacant land; New Delhi, Chandigarh, and Gandhinagar in India are examples of such cities.

\section{Purposes of MAster Plan}

Main goals of the master plan are:

1) Presenting a public image and general planning for future growth of the city.

2) Defining various functions of the city, maintaining necessary physical relations and harmony among different parts so as to reduce confrontations and contradictions between different urban function. This master plan also helps to harmony of diverse social urban groups and classes.

3) Producing more social benefits for the purpose of balanced urban development.

4) Allocation of public budget in an economic and intelligent manner to address the public welfare of urban society [7].

\section{CITY Form AND STRUCTURAL Form}

Outer image of a city is like a signature by which it is recognized. A city's skyline, like a person's handwriting, conveys some information about the nature of it. Proud and glorious arrangement of buildings and their intersection with the form of the land, all appear in an overview when moving toward the city. A beautiful skyline brings honor, glory and joy to citizens and as a practical use it also attracts tourists. After all, it seems that there is a relation between the outer form of a city and its segments, and a relation between a city's skyline and its foundation process. Architecture, along with composition, is both contingent upon and determinative of the constitution of urban artifacts, especially at those times when it is capable of synthesizing the whole civil and political scope of an epoch, when it is highly rational, comprehensive, and transmissible - in other words, when it can be seen as a style. It is at these times that the possibility of transmission is implicit, a transmission that is capable of rendering a style universal. The indetification of particular urban artifacts and cities with a style of architecture is so automatic in certain contexts of space and time that we can speak with discrete precision of the gothic city, the baroque city, the neoclassical city. These stylistic definitions immediately become morphological definitions; they precisely define the nature of urban artifacts. In these terms it is possible to speak of civic design. For this to occur, it is necessary that a moment of decisive historical and political importance coincide with an architecture that is rational and definite in its forms. It is then possible for the community to resolve its problems of choice, to desire collectively one kind of city and to reject another.

\section{CITY SHAPE}

The term City Shape has been examined from many points of view. Buren while in search for a specific definition reviewed many manuscripts and examined the methods that researchers use such terms as city shape and spatial structure, has encountered what he states as diverse variations and disappointing contradictions [8]. One of the major reasons for such variation is that city shape has been examined by many areas; each of those different and diverse approaches pursued the concept of city shape with different definitions and semantic frameworks.

The history of the city is also the history of architecture. But we must remember that the history of architecture is at most one point of view form which to look at the city. The failure to understand this has led to much time spent in studying the city and its architecture in terms of its images, or else an attempt to study the city form the standpoint of other sciences, for example psychology. But what can psychology tell us if not that a certain individuals see it in another? And how can this private and uncultivated vision be related to the laws and principles from which the city first emerged and through which its images were formed if we are concerned with the city architecturally from more than a stylistic point of view, it does not make sense to abandon architecture and occupy ourselves with something else. Indeed, no one would entertain the idea, that when the theoreticians tell us that buildings must respond to criteria of firmness, commodity, and delight, they must explain the psychological motives behind this principle. Leonardo Benevolo tries to interpret urban development based on major developments in the creative organization which revolutionizes daily life and - as a result - on population growth in each era. Major areas of research include the changes in physical environment which is influenced by all other aspects of civilization and in turn it influences them, and the quality of slow-down in changes by past reminiscence and speed-up in changes by modern 
buildings.

Another viewpoint to historical analysis of the city takes it as a natural phenomenon and compares its historical change to biological evolution of the natural world; city as a natural phenomenon, a concept that Tafori traces it back to enlightenment era and evolution of capitalism, is reflected in some designing approaches. Ecological methods are employed by which city is understood as a resulting shape of geological and biological evolution and as a sum total of natural processes adapted by human.

Architecture claims that it is above all other visual arts. Posener states that what is distinguishing architecture from other arts like paintings and sculpture, is its positional value while at the same time it embraces all of these forms of art, so it is the most comprehensive visual art. He also believes in the social excellence of architecture to other forms of visual arts, because we are encompassed by architecture and not able to avoid buildings and their delicate but influential nature (Posener). Because we live in environments made of man-made artifacts, so architecture becomes an "inevitable art". Direct result of such equation between the city and its architecture is that the city is assumed as the biggest work of art (Olsen).

Also, there exists a third angle considering urban design as a creative process which Lynch calls it a chimerical creativity along with the fancy of existing forms. In this process, designers express their positional ideas in the form of a proper design while interacting with their own imaginative world using their aesthetic perception and graphical skills.

Here, among understandable structures which interact with the agent, lies the designer's perception, and the medium and the expressive vehicle [8]. Designer's perception is formed in contact with external world and it consists of a "library" of pictures and real world arrangements which the designer recognizes them as true and beautiful. In designing process, designers often refer to this library most of the time and/or make new combinations of its images to achieve the desired form.

Many incline to view urban design from one of these three angles we have analyzed. Some see it just as a technical process, thus take it equivalent to the Great Architecture. Some take it but a social interaction to achieve new organizational arrangements and as a result concentrating on its management potentials rather than space production. However some others assume it an artistic activity that only talented designers must do; a one-dimensional viewpoint that naturally results to some compliments and limited perspectives at the expense of underestimating the reality and diverse aspects of urban design.

\section{CONCLUSION}

Major characteristics of city shape in twentieth century are growth of metropolitan areas and development of suburbs. Urban planning in its modernity and post-modernity versions, focuses mainly on the city, whether it contributes to pluralism and diversity of city or organizes it. Deterioration of urban centers generates a serious danger for utopian urban planning. Anti-urban trend is a gradual retreat of the middle-class from metropolitans to suburbs. In contrast to such suburban colonization, and its more serious form i.e. urban sprawl (or peri-urbanisation), and as an opposition to unknownness of metropolis, planned cities came to attention as a form of social life; they are supported to present an alternative utopia that is micropolitan areas. In fact, suburbs are now a part of a bigger whole which encompasses the city; downtown and suburbs together make the urban area. So urban planning ought not to eliminate suburbs. Suburban colonization has reached sufficient growth and embraces such population that itself became an indistinguishable part of the city. If urban design supports urban and micro-urban planning, it ought to render the whole urban area. Urban design is not just a tool to beautify urban centers; it is a tool to render whole urban areas with their compositional parts. But such a conclusion only closes the discourse without having accomplished anything if it presumes the relationship between analysis and design to be a problem of the individual architect rather than of te progressof architecture as science. It denies the hope contained in Laborde's remark, that he saw in the new generation of men of art and culture those who had teken up the habit of criticism and observation. In other words, who saw the possibility of a more profound understanding of the structure of the city [9]. It's believed that this kind of study of the object of architecture as it is here understood, as a human creation must precede analysis and design.

\section{REFERENCES}

[1] A. Gutton, Urban Planning for Man, translated by Houshang Naqi, Iranian National University, 1979.

[2] A. Madanipour, Managing Cities: the New Urban Content, Wiley, 1995.

[3] G. K. Hirasker, Introduction to Fundamentals of Urban Planning, translated by Dr. Mohammad Soleimani, Di. Ahmadreza Yekani Fard, 2007.

[4] R. Headman and A. Yaszewski, Fundamentals of Urban Design, translated by Razieh Rezazadeh, Mostafa Abbas Zadegan, Iran University of Science and Technology, 2002.

[5] V. Jacomini, The UNESCO Courier, Iranian National Commission for UNESCO, Tehran, no. 134, 1983.

[6] Rules and Regulations of Urban Space Planning, Iran Urban Planning and Research Center, Tehran.

[7] F. Shuai, Urban Planning, and Imageries and Realities, translated by Seyed Mohsen Habibi, Tehran University, Tehran, 1996.

[8] Urban Systems, The UNESCO Courier, Iranian National Commission for UNESCO, Tehran, no. 208, 1997.

[9] A. Rossi, The Architecture of the city, published by the graham foundation for advanced studies in the fine arts, England, 1982

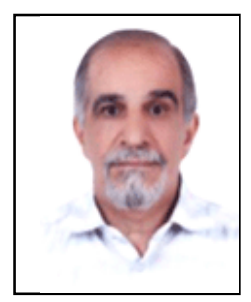

Ali Dashti Shafii was born in Iran, 1949. He recevied his $\mathrm{PhD}$ in architecture Venice, Italy since 1976, he has been a professional urban planner, Venice, Italy in 1977. He has worked over forty years with professional architectural experience. He published with over 100 papers (including 40 ISI essays).

Babak Monir Abbasi holds master degree of architecture from Shabestar, Iran and he teaches at different universities such as Parand Payam Noor, Parand Islamic Azad University. Now he is working with Dr. Dashti on some projects as an assistant.

Shiva Jabari was born in Iran, 1992. She is a scholar at Shomal Univevrsity of Amol, Iran. She has good English language skills, She is Mr. Dashti's editorial assistant. She mainly works as a translator and editor. 